\title{
Wisp1 mediates Bmp3-stimulated mesenchymal stem cell proliferation
}

\author{
Maria Cernea, Wei Tang, Haiyan Guan and Kaiping Yang
}

Departments of Obstetrics and Gynaecology, and Physiology and Pharmacology, Children's Health Research Institute and Lawson Health Research Institute, Western University, Room A5-132, 800 Commissioners Road East, London, Ontario, Canada, N6C 2V5

Correspondence should be addressed to $\mathrm{K}$ Yang Email

kyang@uwo.ca

\begin{abstract}
Adipose tissue expansion, resulting from adipocyte hyperplasia and/or hypertrophy, is a hallmark of obesity. Adipocytes are derived from mesenchymal stem cells (MSCs) through adipogenesis, a process involving three key steps: proliferation, commitment and differentiation. Although studies have elaborated on the mechanisms regulating adipocyte commitment and differentiation, the factors that control MSC proliferation remain largely unknown. Previously, we demonstrated that bone morphogenetic protein 3 (Bmp3), the expression of which was upregulated in our rat model of hyperplasic visceral adiposity, potently stimulated MSC proliferation. In the present study, we investigate the molecular target of Bmp3. We conducted DNA microarray analysis on MSCs treated with and without Bmp3 and identified WNT1-inducible signaling pathway protein 1 (Wisp 1) as a differentially expressed gene, whose expression was upregulated 3.7-fold by Bmp3. Wisp1 is a proliferative agent in various non-adipose cell types and is implicated in adipogenesis. Therefore, we tested the hypothesis that Wisp1 mediates Bmp3 stimulation of MSC proliferation. We showed that Bmp3 increased the expression of Wisp1 as early as $3 \mathrm{~h}$ following Bmp3 treatment in MSCs. Importantly, the upregulated Wisp1 expression preceded Bmp3-induced MSC proliferation, as determined by $\left[{ }^{3} \mathrm{H}\right]$-thymidine incorporation. Furthermore, treatment of MSCs with recombinant Wisp1 led to a concentration-dependent increase in $\left[{ }^{3} \mathrm{H}\right]$-thymidine incorporation with a maximal increase of $300 \%$. In addition, siRNA-mediated knockdown of Wisp1 expression attenuated Bmp3-induced MSC proliferation. Taken together, our present findings reveal Wisp1 as a novel target of $B m p 3$ and suggest that the $B m p 3 / W i s p 1$ signaling pathway play a key role in MSC proliferation, and consequently adipogenesis.
\end{abstract}

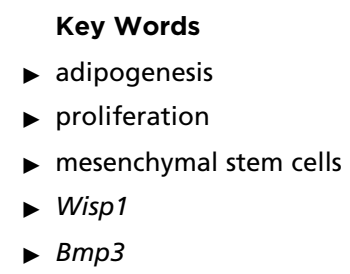

Journal of Molecular Endocrinology (2016) 56, 39-46

\section{Introduction}

Obesity has reached epidemic proportions globally and is a major contributor to the global burden of chronic disease and disability (Dixon 2010, WHO 2015). These obesity-associated co-morbidities include insulin resistance, type-2 diabetes, strokes, hypertension, coronary artery disease, various cancers, chronic kidney disease, osteoarthritis, sleep apnea and premature death. At the cellular level, obesity is characterized by excess adipose tissue expansion resulting from an increase in the adipocyte cell number or adipocyte cell size (Hirsch \& Batchelor 1976, Shepherd et al. 1993). New adipocytes arise from a pre-existing population of undifferentiated progenitor cells, namely mesenchymal stem cells (MSCs), through adipogenesis, a process that involves three key 
steps: proliferation, commitment and terminal differentiation (Moreno-Navarrete \& Fernandez-Real 2012).

Adipocyte number is established during early life by various environmental factors (Spalding et al. 2008) as an adaptation to enhance future fat storage in order to face potential adverse environmental conditions in later life (Hales et al. 1997). In particular, low birth weight has been associated with increased adiposity in humans (Osmond \& Barker 2000) and animal models (Sarr et al. 2012) during adulthood. We have previously shown that poor nutrition during early life, induced by maternal protein restriction (MPR) during pregnancy and lactation, leads to low birth weight and subsequent development of increased visceral adiposity in adult male rat offspring (Guan et al. 2005). This increased visceral adiposity was characterized by adipocyte hyperplasia. Indeed, we showed that adipocyte precursor cells derived from MPR offspring exhibited an accelerated rate of proliferation, and this persisted days after removal from their in vivo environment (Zhang et al. 2007). Based on these observations, we identified Bmp3 (bone morphogenetic protein 3) as a key gene that was increased twofold in the adipose tissue of our MPR rat model of visceral adiposity (Guan et al. 2005). Bmp3 expression was also upregulated in the adipose tissue of a diet-induced mouse model of obesity (Koza et al. 2006). As a member of the transforming growth factor beta (TGF $\beta$ ) superfamily, $B m p 3$ was originally thought to act as a trophic factor for bone growth due to its high expression in bone tissue (Sampath et al. 1987), but subsequent genetargeting studies revealed that $B m p 3$ was anti-osteogenic (Bahamonde \& Lyons 2001). We showed that Bmp3 promoted MSC and preadipocyte proliferation via the TGF $\beta$ /activin-signaling pathway (Stewart et al. 2010). However, the downstream molecular targets through which $B m p 3$ stimulates MSC proliferation remain unknown. Therefore, the present study was designed to address this important question.

\section{Materials and methods}

\section{Cell culture}

The C3H10T1/2 MSC line was obtained from the American Type Culture Collection (Manassas, VA, USA). C3H10T1/2 stem cells were cultured in standard growth medium consisting of Minimal Essential Medium (MEM; Sigma-Aldrich Canada Ltd) and 10\% fetal bovine serum (FBS; Sigma). All cultures were maintained in a humidified incubator at $37^{\circ} \mathrm{C}$ and $5 \% \mathrm{CO}_{2}$. Growth medium was replaced every other day.

\section{Genome-wide gene expression profiling: DNA microarray}

C3HT10T1/2 MSCs were treated with and without $100 \mathrm{ng} / \mathrm{ml}$ recombinant human $B m p 3$ (R\&D Systems, Minneapolis, MN, USA) for $6 \mathrm{~h}$. At the end of treatment, total RNA was extracted from cultured cells using RNeasy Mini Kit (QIAGEN, Inc., Mississauga, ON, Canada) coupled with on-column DNase digestion with the RNase-Free DNase Set (QIAGEN) according to the manufacturer's instructions. A total of four arrays (GeneChip Mouse Genome 430 2.0 Array; Affymetrix, Santa Clara, CA, USA) were conducted using total RNA samples from two control and two Bmp3-treated sets of cells, as previously described (Guan et al. 2005). Briefly, microarrays were performed at the London Regional Genomics Centre (London, ON, Canada) following the standard procedures as outlined in the Affymetrix GeneChip Expression Analysis Technical Manual. The complete data set was submitted to the National Center for Biotechnology Information's Gene Expression Omnibus (GEO; http://www.ncbi.nlm.nih.gov/geo/) database (acc. no. GSE73649). Expression values for the Affymetrix GeneChip data were globally normalized to a preset value and analyzed using GeneSpring version 10.0 Software (Silicon Genetics, Redwood City, CA, USA). Values for the mean expression level for each gene were calculated for the control and $B m p 3$ treatment microarray data sets. Candidate genes were selected by a combination of statistical analysis $(P<0.05)$ and comparison analysis (displayed $>1.5$-fold increase or decrease from the control to $B m p 3$ treatment).

\section{Assessment of mRNA levels: real-time quantitative RT-PCR}

The relative abundance of various mRNAs was assessed by a two-step real-time quantitative RT-PCR (qRT-PCR), as described previously (Rajakumar et al. 2015). Briefly, $1 \mu \mathrm{g}$ of total RNA was reverse-transcribed in a total volume of $20 \mu \mathrm{l}$ using the High Capacity cDNA Archive Kit (Applied Biosystems) following the manufacturer's instructions. For every RT reaction set, one RNA sample was set up without reverse-transcriptase enzyme to provide a negative control. Gene transcript levels of Gapdh (housekeeping gene), Wisp1 (CCN; human gene nomenclature), Cyr61 (CCN1), Ctgf (CCN2), Nov (CCN3), Wisp2 (CCN5), and Wisp3 (CCN6) were quantified separately by predesigned and validated TaqMan Gene Expression Assays (Applied Biosystems; Table 1) following the manufacturer's instructions. Briefly, gene expression assays were performed with the TaqMan Gene Expression Master Mix

Published by Bioscientifica Ltd. 
Table 1 TaqMan gene expression assays for various mouse genes.

\begin{tabular}{l} 
Gene name \\
\hline Ctgf \\
Cyr61 \\
Gapdh \\
Nov \\
Wisp1 \\
Wisp2 \\
Wisp3 \\
Gapdh
\end{tabular}

\begin{tabular}{l}
\hline Assay ID \\
\hline Mm01192931_g1 \\
Mm00487498_m1 \\
Mm99999915_g1 \\
Mm00456855_m1 \\
Mm00457574_m1 \\
Mm00497471_m1 \\
Mm01193670_m1 \\
Mm99999915_g1
\end{tabular}

(Applied Biosystems; $\mathrm{P} / \mathrm{N}$ \#4369016) and the universal thermal cycling condition $\left(2 \mathrm{~min}\right.$ at $50^{\circ} \mathrm{C}$ and $10 \mathrm{~min}$ at $95^{\circ} \mathrm{C}$, followed by 40 cycles of $15 \mathrm{~s}$ at $95^{\circ} \mathrm{C}$ and $1 \mathrm{~min}$ at $60^{\circ} \mathrm{C}$ ) on the ViiA 7 Real-Time PCR System (Applied Biosystems).

The relative amount of various gene specific mRNAs in each RNA sample was quantified by the comparative $\mathrm{C}_{\mathrm{T}}$ method (also known as $\Delta \Delta \mathrm{C}_{\mathrm{T}}$ method) using the Applied Biosystems relative quantitation and analysis software according to the manufacturer's instructions. For each experiment, the amount of various gene specific mRNAs under different treatment conditions is expressed relative to the amount of transcript present in the untreated control.

\section{Proliferation assay: $\left[{ }^{3} \mathrm{H}\right]$-thymidine incorporation}

Proliferation capacity of C3H10T1/2 MSCs was assessed by measuring $\left[{ }^{3} \mathrm{H}\right]$-thymidine incorporation, as described previously (Stewart et al. 2010). Briefly, C3H10T1/2 cells were plated at low density (20-30\% confluence) on 24 -well plates and cultured in growth medium for 2-3 days until $50-60 \%$ confluence. Cells were growth-arrested in serumfree medium for $24 \mathrm{~h}$ and were then treated in the serumfree medium with $100 \mathrm{ng} / \mathrm{ml}$ of $\mathrm{Bmp} 3$ for various times $(3,6,12$ and $24 \mathrm{~h})$ or increasing concentrations of mouse recombinant Wisp1 (0.1-2 $\mu \mathrm{g} / \mathrm{ml}$; Cat \#1680WS, R\&D Systems) for $24 \mathrm{~h}$. During the last $4 \mathrm{~h}$ of treatment, cells were pulsed labeled with $\left[{ }^{3} \mathrm{H}\right]$-thymidine $(0.5 \mu \mathrm{Ci} /$ well; 75.2 Ci/mmol, PerkinElmer Life and Analytical Sciences, Woodbridge, ON, Canada). Cells were washed twice with ice-cold PBS, once with 5\% trichloroacetic acid (TCA) and twice with $95 \%$ ethanol. Cells were then solubilized by the addition of $400 \mu \mathrm{l}$ of $0.5 \mathrm{M} \mathrm{NaOH}$. The solubilized cell lysate $(300 \mu \mathrm{l})$ was added to $4 \mathrm{ml}$ of scintillation fluid and the incorporation of $\left[{ }^{3} \mathrm{H}\right]$-thymidine into DNA was determined by scintillation counting. Results were expressed as a percentage of control.

\section{Western blot analysis}

Western blot analysis was used to determine WISP1 protein levels, as described previously (Stewart et al. 2010). Briefly, C3H10T1/2 stem cells were lysed in SDS Sample Buffer (62.5 mM Tris-HCl, pH 6.8, 2\% w/v SDS, $10 \% \mathrm{v} / \mathrm{v}$ glycerol, $50 \mathrm{mM}$ DTT and $0.01 \% \mathrm{w} / \mathrm{v}$ bromophenol blue). Equal concentrations of the whole cell lysates were subjected to a standard 10\% SDS-PAGE. After electrophoresis, proteins were transferred to PVDF transfer membrane (Amersham Hybond-P, Cat\# RPN303F) using a Bio-Rad Mini Transfer Apparatus. Non-specific antibody binding was blocked with $5 \% \mathrm{w} / \mathrm{v}$ milk in TTBS $(0.1 \% \mathrm{v} / \mathrm{v}$ Tween-20 in TBS) for $1 \mathrm{~h}$ at room temperature. Membranes were then hybridized with primary antibody (WISP1 polyclonal antibody at 1:2000, CAT\# PAB7404, Abnova, Taoyuan City, Taiwan; human GAPDH polyclonal antibody at 1:5000, Cat\# IMG- 5567, Imgenex Corporation, San Diego, CA, USA) overnight at $4{ }^{\circ} \mathrm{C}$. After three 10-min washes with TTBS, the membrane was incubated with the appropriate HRP-labeled secondary antibody, either anti-Goat (Cat\# AP180P, Millipore, Etobicoke, ON, Canada, 1:10 000) or anti-rabbit (R\&D Systems, Cat\# HAF008, 1:1000) for $1 \mathrm{~h}$ at room temperature. Following another three 10-min washes in TTBS, proteins were detected by chemiluminescence (Western Lightning Plus-ECL, PerkinElmer Life and Analytical Sciences, Cat\# NEL103001). The membrane was then exposed to X-ray film (Eastman Kodak, Rochester, NY, USA) for 1-60 min.

\section{The siRNA-mediated knockdown of Wisp1 expression}

To provide direct evidence for the involvement of Wisp1 in mediating the effects of $B m p 3$ on MSC proliferation, a siRNA-mediated knockdown approach was utilized (Guan et al. 2013). Briefly, C3H10T1/2 MSCs were plated on 24-well plates and cultured under standard conditions for $48 \mathrm{~h}$. Cells were then transfected $100 \mathrm{nM}$ of the Silencer Select Pre-designed siRNA-targeting mouse Wisp1 (CAT\# S76051; Ambion) in Opti-MEM I medium (Invitrogen) containing $2 \mu \mathrm{l} /$ well of Lipofectamine 2000 (Invitrogen), following the manufacturer's instructions. Cells were also transfected in an identical manner with $100 \mathrm{nM}$ of the negative control \#1 siRNA (Cat\# 4624; Ambion) or with the transfection agent alone to serve as controls. At $48 \mathrm{~h}$ post-transfection, cells were collected for western blot analysis. Alternatively, $12 \mathrm{~h}$ after transfection, cells were treated for $48 \mathrm{~h}$ with $100 \mathrm{ng} / \mathrm{ml} \mathrm{Bmp3}$. At the end of treatment, proliferation capacity was determined by $\left[{ }^{3} \mathrm{H}\right]$ thymidine incorporation, as described above.

Published by Bioscientifica Ltd. 


\section{Statistical analysis}

Results are presented as mean \pm s.E.M. of four independent experiments each performed in triplicate. Data were analyzed using one-way ANOVA followed by Tukey's post-hoc test, or Student's t-test as indicated. Significance was set at $P<0.05$.

\section{Results}

\section{Effects of Bmp3 on MSC transcriptome}

As a first step in identifying the downstream factors that are responsible for mediating Bmp3-induced MSC proliferation, we conducted genome-wide gene expression profiling and identified 134 and 164 genes that were up- and downregulated by Bmp3 respectively (data not shown). Among the significantly upregulated genes, WNT-inducible secreted protein 1 (Wisp1/CCN4), whose expression was upregulated 3.7-fold by Bmp3 (Fig. 1A), was of
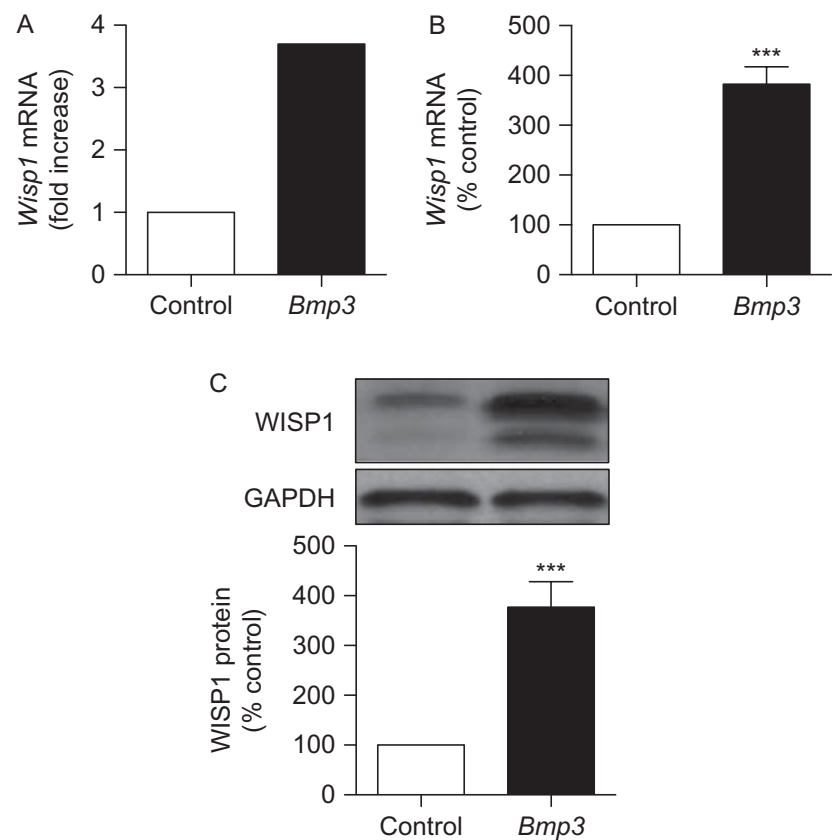

\section{Figure 1}

Effects of Bmp3 on transcriptome and Wisp1 expression. C3H10T1/2 mesenchymal stem cells were treated with $100 \mathrm{ng} / \mathrm{ml}$ recombinant $B m p 3$ for $6 \mathrm{~h}$. At the end of treatment, total RNA was isolated and subjected to standard DNA microarray analysis using Affymetrix Gene Expression Arrays. Wisp1 was one of the most upregulated genes, the expression of which was increased 3.7-fold by Bmp3 (A). The same RNA samples were then subjected to qRT-PCR using pre-designed and validated TaqMan Gene Expression Assays to verify the increased expression of Wisp1 as revealed by DNA microarray $(B ; * * P<0.001$ vs control). Alternatively, at the end of $B m p 3$ treatment, cells were lysed and levels of WISP1 protein were determined by western blotting $\left(C_{;} * * * P<0.001\right.$ vs control). particular interest, because it has been previously shown to promote proliferation of cardiac fibroblasts (Venkatachalam et al. 2009), lung epithelial cells (Königshoff et al. 2009) and osteogenic cells (Inkson et al. 2009). Consequently, we selected Wisp1 as a potential candidate gene and verified the magnitude of the increase in levels of Wisp1 mRNA following Bmp3 treatment with qRT-PCR (Fig. 1B; $P<0.001$ ). Importantly, we showed that there was a corresponding increase in levels of WISP1 protein (Fig. 1C; $P<0.001$ ).

\section{Effects of Bmp3 on the expression of CCN family genes}

Wisp1 belongs to the $C C N$ family genes, which include Cyr61 (CCN1), Ctgf (CCN2), Nov (CCN3), Wisp2 (CCN5), and Wisp3 (CCN6) (mouse and human gene nomenclatures, respectively). To establish whether the effects of Bmp3 were specific to Wisp1, we determined mRNA levels of all six CCN family genes by qRT-PCR. We showed that mRNA levels of Cry61, Ctgf and Wisp1 were increased by 1.7-, 6.5- and 4.1-fold following Bmp3 treatment respectively (Fig. 2). By contrast, the mRNA level of Nov, Wisp2 and Wisp3 were unchanged following Bmp3 treatment (Fig. 2).

\section{Effects of Bmp3 on Wisp1 expression and MSC proliferation}

Given that Wisp1 was upregulated following Bmp3 treatment and is a known pro-survival factor in various nonadipose cell types (Inkson et al. 2009, Königshoff et al. 2009, Venkatachalam et al. 2009, Schlegelmilch et al. 2014), coupled with previous findings that human adipocyte differentiation was associated with elevated Wisp1 expression (Murahovschi et al. 2015), we examined the involvement of Wisp1 in mediating Bmp3-induced MSC proliferation. We first determined if Bmp3-induced upregulation of Wisp1 expression preceded Bmp3-stimulated cell proliferation by conducting a time-dependent experiment. We showed that Bmp3 increased Wisp1 mRNA as early as $3 \mathrm{~h}$, while an increase in $\left[{ }^{3} \mathrm{H}\right]$-thymidine incorporation was not observed until $12 \mathrm{~h}$ post-treatment (Fig. 3A and B).

\section{Effects of Wisp1 on MSC proliferation}

To determine if Wisp1 stimulates MSC proliferation, we treated C3H10T1/2 MSCs with various concentrations of recombinant Wisp1 and assessed cell proliferation by standard $\left[{ }^{3} \mathrm{H}\right]$-thymidine incorporation assays. We showed that Wisp1 increased $\left[{ }^{3} \mathrm{H}\right]$-thymidine incorporation in a

Published by Bioscientifica Ltd 


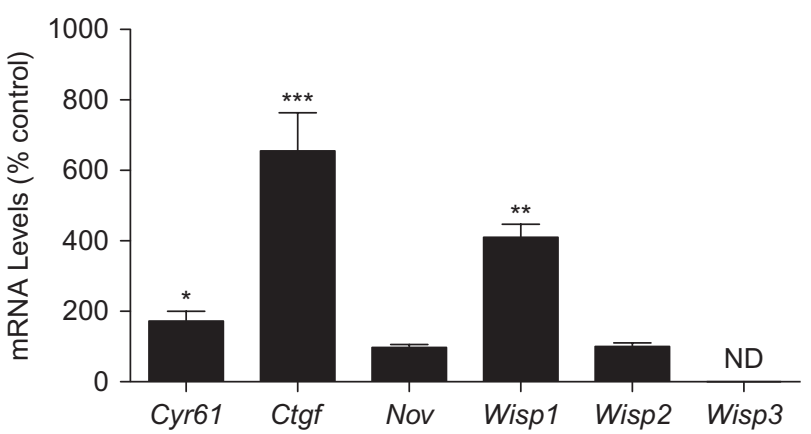

Figure 2

Effects of Bmp3 on the expression of CCN family genes. C3H10T1/2 mesenchymal stem cells were treated with $100 \mathrm{ng} / \mathrm{ml}$ recombinant $B m p 3$ for $6 \mathrm{~h}$. At the end of treatment, total RNA was isolated, and individual mRNA levels were determined by qRT-PCR using pre-designed and validated TaqMan Gene Expression Assays. Each bar represents mean \pm S.E.M. of four independent experiments each performed in triplicate ( ${ }^{*} P<0.05, * * P<0.01$ and $* * * P<0.001$ vs control). ND, not detectable.

concentration-dependent manner, with a maximal effect at $1 \mu \mathrm{g} / \mathrm{ml}$, and to a similar degree as Bmp3 (>3-fold increase; Fig. 4).

\section{Effects of siRNA-mediated knockdown of Wisp1 expression on Bmp3 stimulation of MSC proliferation}

To provide direct evidence for the involvement of Wisp1 in mediating Bmp3-induced MSC proliferation, we transfected C3H10T1/2 MSCs with siRNA specific for mouse Wisp1 and examined the effect of Bmp3 on $\left[{ }^{3} \mathrm{H}\right]$-thymidine incorporation. As shown in Fig. 5, transfection of the cells with Wisp1-specific siRNA resulted in an $80 \%$ reduction in WISP1 protein levels. Furthermore, siRNA-mediated knockdown of Wisp1 expression significantly attenuated the stimulatory effect of $B m p 3$ on $\left[{ }^{3} \mathrm{H}\right]$-thymidine incorporation (from $>350$ to $150 \%$ of control) (Fig. 5C).

\section{Discussion}

In the present study, we demonstrate that i) $\mathrm{Bmp} 3$ induces dynamic changes in C3H10T1/2 MSC transcriptome, including a significant increase in the expression of Wisp1, a key pro-survival factor previously identified in non-adipose cells (Venkatachalam et al. 2009, Schlegelmilch et al. 2014); ii) Bmp3-induced upregulation of Wisp1 expression proceeds Bmp3-stimulated MSC proliferation; iii) recombinant Wisp1 potently stimulates MSC proliferation; and iv) siRNA-mediated knockdown of Wisp1 expression significantly attenuates the stimulatory effect of $B m p 3$ on MSC proliferation. Taken together, these findings reveal Wisp1 as a novel target of $B m p 3$, and demonstrate that the Bmp3/Wisp1 signaling pathway plays an important role in MSC proliferation. However, the physiological significance of these findings in vivo remains to be determined.

Although accelerated adipogenesis is a hallmark of obesity, the precise molecular mechanisms and factors that govern adipogenesis are incompletely understood. Adipogenesis begins with the commitment of MSCs to the adipocyte lineage, followed by terminal differentiation of preadipocytes to lipid-filled mature adipocytes (Rosen \& MacDougald 2006, James 2013). Prior to these stages
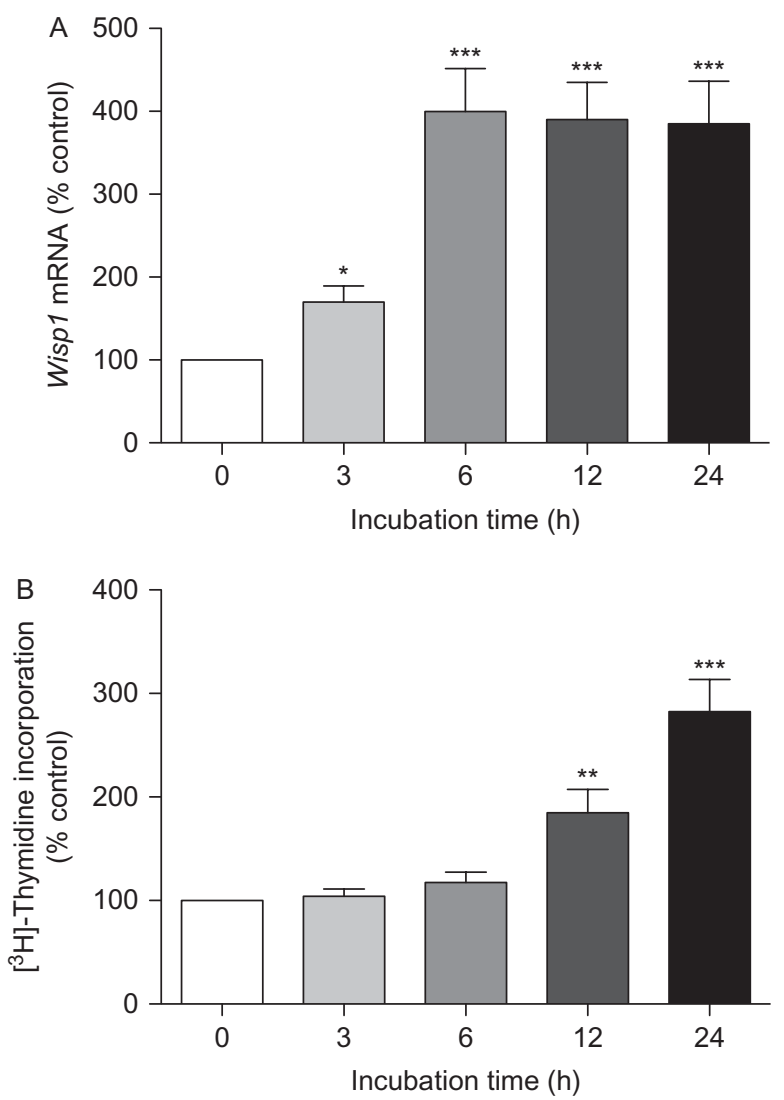

Figure 3

Time-dependent effects of Bmp3 on Wisp1 expression and cell proliferation. C3H10T1/2 mesenchymal stem cells were treated with $100 \mathrm{ng} / \mathrm{ml}$ recombinant $B m p 3$ for various times. At the end of treatment, total RNA was isolated, and levels of Wisp1 mRNA (A) were determined by qRT-PCR using pre-designed and validated TaqMan Gene Expression Assays. Alternatively, cell proliferation (B) was assessed by a standard $\left[{ }^{3} \mathrm{H}\right]$ thymidine incorporation assay, as described in the section 'Materials and methods'. Each point represents mean \pm s.E.M. of four independent experiments each performed in triplicate $(* P<0.05, * * P<0.01$ and $* * * P<0.001$ vs control).

Published by Bioscientifica Ltd. 


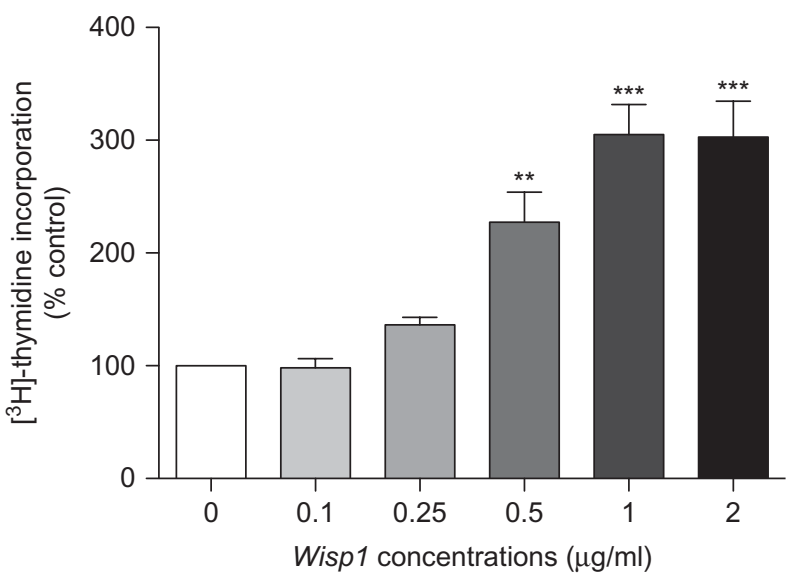

Figure 4

Effects of Wisp 1 on cell proliferation. C3H10T1/2 mesenchymal stem cells were treated with increasing concentrations of recombinant Wisp1 for $24 \mathrm{~h}$. At the end of treatment, cell proliferation was assessed by a standard $\left[{ }^{3} \mathrm{H}\right]$-thymidine incorporation assay, as described in the section 'Materials and methods'. Each point represents mean \pm s.E.M. of four independent experiments each performed in triplicate $\left({ }^{* *} P<0.01\right.$ and $* * * P<0.001$ vs control).

however, MSCs undergo proliferation, a process that is critical but poorly understood (Rosen \& MacDougald 2006, Moreno-Navarrete \& Fernandez-Real 2012). We previously showed that $B m p 3$ stimulated MSC proliferation via the TGF- $\beta$ /activin-signaling pathway (Stewart et al. 2010). In this study, we sought to identify the downstream molecular targets that mediate Bmp3induced MSC proliferation. Using DNA microarray, we first identified genes that were differentially regulated by Bmp3. Prominently among the upregulated genes was Wisp1, the increased expression of which is known to be associated with human adipocyte differentiation (Murahovschi et al. 2015). Wisp1 is also a pro-survival factor, because it stimulates proliferation of several non-adipose cell types, including cardiac fibroblasts (Venkatachalam et al. 2009), lung epithelial cells (Königshoff et al. 2009), osteogenic cells (Inkson et al. 2009). Furthermore, reduced expression of Wisp 1 is associated with enhanced apoptosis in cultured human mesenchymal stromal cells (Schlegelmilch et al. 2014). Therefore, we chose Wisp1 as a candidate gene for this study. We first confirmed the upregulated expression of Wisp 1 by Bmp3 with qRT-PCR and western blotting. We then determined if the effects of $B m p 3$ were specific to Wisp1 or the entire $C C N$ family of genes. Our results indicated that $B m p 3$ discretely upregulated the expression of two other CCN family genes, Cyr61 and Ctgf, while expression of the remaining members of $C C N$ family was unchanged. To the best of our knowledge, this is the first study to identify certain members of the $C C N$ family as downstream targets of Bmp3. Although Cyr61 has been shown to play a crucial role in cutaneous wound healing (Jun \& Lau 2010), while Ctgf is a known mediator of organ fibrosis (Chen \& Lau 2009), the functional significance of Bmp3-induced upregulation of Cyr61 and Ctgf awaits future exploration.

Our next step was to examine the involvement of Wisp1 in mediating Bmp3-induced MSC proliferation.
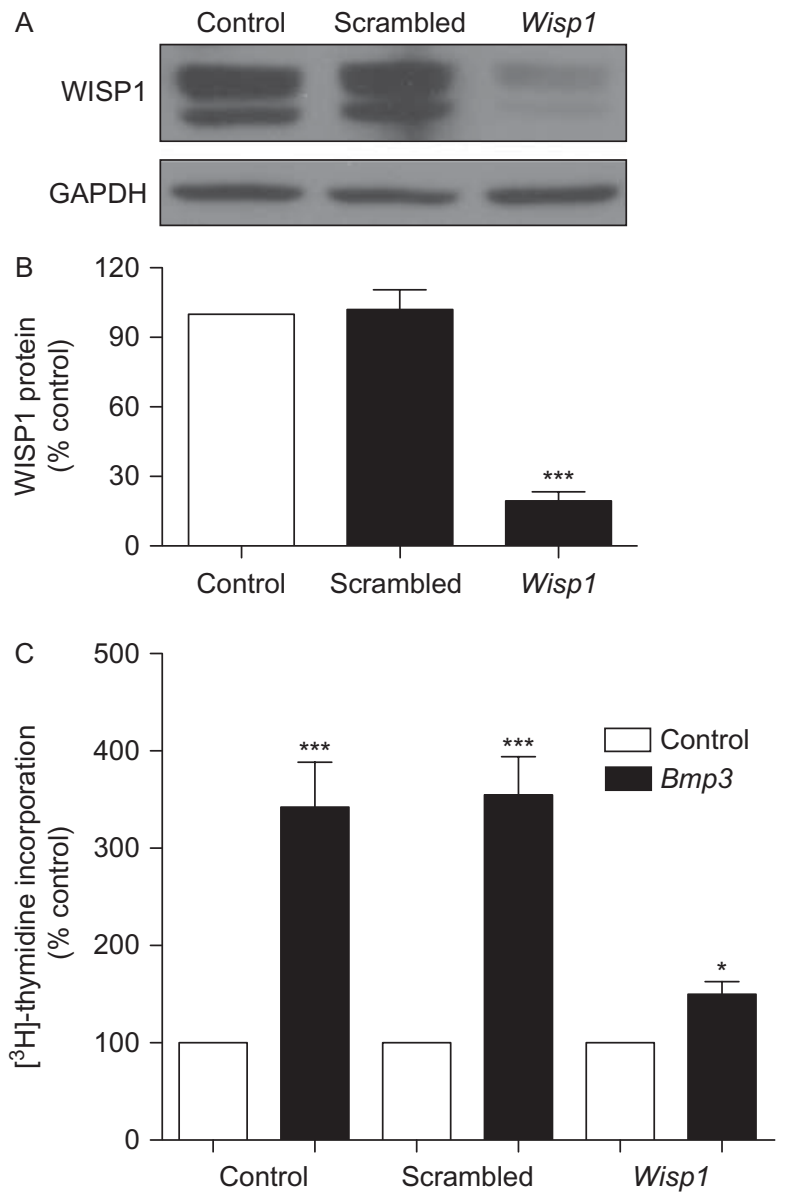

Figure 5

Effects of siRNA-mediated knockdown of Wisp1 expression on Bmp3 stimulation of cell proliferation. C3H10T1/2 mesenchymal stem cells were plated on 24-well plates and cultured under standard conditions for $48 \mathrm{~h}$. Cells were then transfected with scrambled siRNA or siRNA specific for mouse Wisp1, as described in the section 'Materials and methods'. Forty-eight hours after transfection, levels of WISP1 protein were determined by western blotting ( $A$ and $B$ ). Alternatively, cells were treated with $100 \mathrm{ng} / \mathrm{ml}$ recombinant $B m p 3$ for $24 \mathrm{~h}$, and the rate of proliferation was assessed by a standard $\left[{ }^{3} \mathrm{H}\right]$-thymidine incorporation assay (C), as described the section 'Materials and methods'. Each point represents mean \pm S.E.M. of four independent experiments each performed in triplicate $(* P<0.05$ and $* * * P<0.001$ vs control).

Published by Bioscientifica Ltd. 
By conducting a time-dependent experiment, we determined that $B m p 3$ upregulated the expression of Wisp 1 before stimulating cell proliferation, suggesting the involvement of Wisp1 in mediating BMP3 stimulation of MSC proliferation. To provide direct evidence in support of this contention, we showed that treatment with recombinant Wisp1 led to a concentration-dependent increase in MSC proliferation. This is consistent with the findings of two previous studies showing that Wisp1 was a proliferative factor in human MSCs, aiding in bone development (Thorfve et al. 2014) and fracture repair (French et al. 2004).

To provide additional evidence for the involvement of Wisp1 in mediating Bmp3-induced MSC proliferation, we used a loss-of-gene function approach. We found that siRNA-mediated knockdown of Wisp1 expression significantly attenuated the stimulatory effect of $B m p 3$ on MSC proliferation, indicating that Wisp1 is a key mediator of $B m p 3$ stimulation of MSC proliferation. Given that the knockdown of Wisp1 expression did not completely block Bmp3-induced MSC proliferation, it is possible that factors other than Wisp1 may also be involved in mediating the effects of $B m p 3$. It is also probable that the incomplete knockdown of Wisp1 expression may account for the incomplete blockade of $B m p 3$-induced MSC proliferation. It is interesting to note that the stimulatory effects of Wisp1 on vascular smooth muscle cell proliferation was attenuated but not prevented by siRNA-mediated knockdown of Wisp1 expression (Liu et al. 2013). Obviously, future studies will be required to explore these possibilities.

In the past several decades, Wisp1 has emerged as a prominent pro-survivor and proliferative factor (Venkatachalam et al. 2009, Maiese 2014). Importantly, aberrant function or dysregulation of the Wisp1 signaling is associated with a variety of disorders, including musculoskeletal, vascular and neurodegenerative (Maiese 2014), as well as various cancers (Gurbuz \& Chiquet-Ehrismann 2015), including breast (Chiang et al. 2015), prostate (Ono et al. 2013) and gastrointestinal (White et al. 2012). In the present study, we identify Wisp1 as a novel mediator of Bmp3-induced MSC proliferation, a key but poorly understood component of adipogenesis. We recognize that MSCs can give rise to four distinct cell types, including adipocytes, chondrocytes, myocytes and osteocytes (Rosen \& MacDougald 2006). As such, it is possible that increased MSC proliferation may have implications for the commitment and differentiation of these pluripotent MSCs to any of the four diverse cell types. However, we have provided evidence to support the contention that stimulation of MSC proliferation by the Bmp3/Wisp1 signaling pathway is a mechanism important to adipogenesis. We previously demonstrated that $B m p 3$ was upregulated in the adipose tissue of an experimental rat model of visceral adiposity and promoted proliferation of both MSCs and 3T3-L1 preadipocytes (Stewart et al. 2010). In the present study, we show that $B m p 3$ potently stimulates the expression of Wisp1, which precedes Bmp3-induced MSC proliferation. We also demonstrate that Wisp1 stimulates MSC proliferation to the same degree as Bmp3. Our contention is also corroborated by a recent study that showed that the expression of Wisp1 was associated with adipocyte differentiation and was elevated in the visceral adipose tissue of obese humans (Murahovschi et al. 2015). However, the question of whether Wisp1 stimulates adipogenic differentiation of MSCs as well as the receptor and the signaling pathway that mediates the effects of Wisp1 remain to be determined. In conclusion, our present findings reveal that the Bmp3/Wisp1 signaling pathway plays a key role in MSC proliferation and may also have important implications for adipogenesis and the pathogenesis of obesity.

\section{Declaration of interest}

The authors declare that there is no conflict of interest that could be perceived as prejudicing the impartiality of the research reported.

\section{Funding}

This work was supported by the Canadian Institutes of Health Research (Operating Grant \#MOP-111158).

\section{Acknowledgements}

M C was the recipient of a Children's Health Foundation Fellowship.

\section{References}

Bahamonde ME \& Lyons KM 2001 BMP3: to be or not to be a BMP. Journal of Bone and Joint Surgery. American Volume 83 S56-S62.

Chen CC \& Lau LF 2009 Functions and mechanisms of action of CCN matricellular proteins. International Journal of Biochemistry \& Cell Biology 41 771-783. (doi:10.1016/j.biocel.2008.07.025)

Chiang KC, Yeh CN, Chung LC, Feng TH, Sun CC, Chen MF, Jan YY, Yeh TS \& Chen SC 2015 WNT-1 inducible signaling pathway protein-1 enhances growth and tumorigenesis in human breast cancer. Scientific Reports 5 8686. (doi:10.1038/srep08686)

Dixon JB 2010 The effect of obesity on health outcomes. Molecular and Cellular Endocrinology 316 104-108. (doi:10.1016/j.mce.2009.07.008)

French DM, Kaul RJ, D'Souza AL, Crowley CW, Bao M, Frantz GD, Filvaroff EH \& Desnoyers L 2004 WISP-1 is an osteoblastic regulator expressed during

Published by Bioscientifica Ltd. 
skeletal development and fracture repair. American Journal of Pathology 165 855-867. (doi:10.1016/S0002-9440(10)63348-2)

Guan H, Arany E, van Beek JP, Chamson-Reig A, Thyssen S, Hill DJ \& Yang K 2005 Adipose tissue gene expression profiling reveals distinct molecular pathways that define visceral adiposity in offspring of maternal protein-restricted rats. American Journal of Physiology. Endocrinology and Metabolism 288 E663-E673. (doi:10.1152/ajpendo. 00461.2004)

Guan H, Sun K \& Yang K 2013 The ERK1/2 signaling pathway regulates 11ß-hydroxysteroid dehydrogenase type 2 expression in human trophoblast cells through a transcriptional mechanism. Biology of Reproduction 89 92. (doi:10.1095/biolreprod.113.110924)

Gurbuz I \& Chiquet-Ehrismann R 2015 CCN4/WISP1 (WNT1 inducible signaling pathway protein 1): a focus on its role in cancer. International Journal of Biochemistry \& Cell Biology 62 142-146. (doi:10.1016/j.biocel. 2015.03.007)

Hales CN, Desai M \& Ozanne SE 1997 The thrifty phenotype hypothesis: how does it look after 5 years? Diabetic Medicine 14 189-195. (doi:10. 1002/(SICI)1096-9136(199703)14:3<189::AID-DIA325 > 3.0.CO;2-3)

Hirsch J \& Batchelor B 1976 Adipose tissue cellularity in human obesity. Journal of Clinical Endocrinology and Metabolism 5 299-311. (doi:10. 1016/S0300-595X(76)80023-0)

Inkson CA, Ono M, Bi Y, Kuznetsov SA, Fisher LW \& Young MF 2009 The potential functional interaction of biglycan and WISP-1 in controlling differentiation and proliferation of osteogenic cells. Cells, Tissues, Organs 189 153-157. (doi:10.1159/000151377)

James AW 2013 Review of signaling pathways governing MSC osteogenic and adipogenic differentiation. Scientifica 2013 684736. (doi:10.1155/ 2013/684736)

Jun JI \& Lau LF 2010 The matricellular protein CCN1 induces fibroblast senescence and restricts fibrosis in cutaneous wound healing. Nature Cell Biology 12 676-685. (doi:10.1038/ncb2070)

Königshoff M, Kramer M, Balsara N, Wilhelm J, Amarie OV, Jahn A, Rose F, Fink L, Seeger W, Schaefer L et al. 2009 WNT1-inducible signaling protein-1 mediates pulmonary fibrosis in mice and is upregulated in humans with idiopathic pulmonary fibrosis. Journal of Clinical Investigation 119 772-787. (doi:10.1172/JCI33950)

Koza RA, Nikonova L, Hogan J, Rim JS, Mendoza T, Faulk C, Skaf J \& Kozak LP 2006 Changes in gene expression foreshadow diet-induced obesity in genetically identical mice. PLoS Genetics 2 e81. (doi:10.1371/ journal.pgen.0020081)

Liu H, Dong W, Lin Z, Lu J, Wan H, Zhou Z \& Liu Z 2013 CCN4 regulates vascular smooth muscle cell migration and proliferation. Molecules and Cells 36 112-118. (doi:10.1007/s10059-013-0012-2)

Maiese K 2014 WISP1: clinical Insights for a proliferative and restorative member of the CCN family. Current Neurovascular Research 11 378-389. (doi:10.2174/1567202611666140912115107)

Moreno-Navarrete JM \& Fernandez-Real JM 2012 Adipose Tissue Biology; Chapter 2: Adipocyte Differentiation, pp 17-32. Ed. ME Symonds. Berlin, Germany: Springer Science+ Business Media.

Murahovschi V, Murahovschi V, Pivovarova O, Ilkavets I, Dmitrieva RM, Döcke S, Keyhani-Nejad F, Döcke S, Keyhani-Nejad F, Gögebakan Ö et al. 2015 WISP1 is a novel adipokine linked to inflammation in obesity. Diabetes 64 856-866. (doi:10.2337/db14-0444)

Ono M, Inkson CA, Sonn R, Kilts TM, de Castro LF, Maeda A, Fisher LW, Robey PG, Berendsen AD, Li L et al. 2013 WISP1/CCN4: a potential target for inhibiting prostate cancer growth and spread to bone. PLoS ONE 8 e71709. (doi:10.1371/journal.pone.0071709)

Osmond C \& Barker DJ 2000 Fetal, infant, and childhood growth are predictors of coronary heart disease, diabetes, and hypertension in adult men and women. Environmental Health Perspectives 108 545-553. (doi:10.1289/ehp.00108s3545)

Rajakumar C, Guan H, Langlois D, Cernea M \& Yang K 2015 Bisphenol A disrupts gene expression in human placental trophoblast cells. Reproductive Toxicology 53 39-44. (doi:10.1016/j.reprotox.2015.03.001)

Rosen ED \& MacDougald OA 2006 Adipocyte differentiation from the inside out. Nature Reviews. Molecular Cell Biology 7 885-896. (doi:10.1038/nrm2066)

Sampath TK, Muthukumaran N \& Reddi AH 1987 Isolation of osteogenin, an extracellular matrix-associated, bone-inductive protein, by heparin affinity chromatography. PNAS 84 7109-7113. (doi:10.1073/pnas.84. 20.7109)

Sarr O, Yang K \& Regnault TR 2012 In utero programming of later adiposity: the role of fetal growth restriction. Journal of Pregnancy 2012134758. (doi:10.1155/2012/134758)

Schlegelmilch K, Keller A, Zehe V, Hondke S, Schilling T, Jakob F \& Klein-Hitpass L 2014 WISP 1 is an important survival factor in human mesenchymal stromal cells. Gene $\mathbf{5 5 1}$ 243-254. (doi:10.1016/j.gene. 2014.09.002)

Shepherd PR, Gnudi L, Tozzo E, Yang H, Leach F \& Kahn BB 1993 Adipose cell hyperplasia and enhanced glucose disposal in transgenic mice overexpressing GLUT4 selectively in adipose tissue. Journal of Biological Chemistry 268 22243-22246.

Spalding KL, Arner E, Westermark PO, Bernard S, Buchholz BA, Bergmann O, Blomqvist L, Hoffstedt J, Näslund E, Britton T et al. 2008 Dynamics of fat cell turnover in humans. Nature $\mathbf{4 5 3} 783-787$. (doi:10.1038/nature06902)

Stewart A, Guan H \& Yang K 2010 BMP-3 promotes mesenchymal stem cell proliferation through the TGF- $\beta$ /activin signaling pathway. Journal of Cellular Physiology 223 658-666. (doi:10.1002/jcp.22064)

Thorfve A, Lindahl C, Xia W, Igawa K, Lindahl A, Thomsen P, Palmquist A $\&$ Tengvall P 2014 Hydroxyapatite coating affects the Wnt signaling pathway during peri-implant healing in vivo. Acta Biomaterialia 10 1451-1462. (doi:10.1016/j.actbio.2013.12.012)

Venkatachalam K, Venkatesan B, Valente AJ, Melby PC, Nandish S, Reusch JE, Clark RA \& Chandrasekar B 2009 WISP1, a pro-mitogenic, pro-survival factor, mediates tumor necrosis factor- $\alpha$ (TNF- $\alpha$ )-stimulated cardiac fibroblast proliferation but inhibits TNF- $\alpha$-induced cardiomyocyte death. Journal of Biological Chemistry 284 14414-14427. (doi:10.1074/jbc.M809757200)

White BD, Chien AJ \& Dawson DW 2012 Dysregulation of Wnt/ $\beta$-catenin signaling in gastrointestinal cancers. Gastroenterology 142 219-232. (doi:10.1053/j.gastro.2011.12.001)

World Health Organization (WHO) 2015 Obesity and overweight: Key facts. World Health Organization fact sheet N311. Geneva, Switzerland: World Health Organization. (available at: http://www.who.int/ mediacentre/factsheets/fs311/en/).

Zhang T, Guan H, Arany E, Hill DJ \& Yang K 2007 Maternal protein restriction permanently programs adipocyte growth and development in adult male rat offspring. Journal of Cellular Biochemistry 101 381-388. (doi:10.1002/jcb.21176)

Received in final form 14 October 2015

Accepted 21 October 2015

Accepted Preprint published online 21 October 2015 http://jme.endocrinology-journals.org

DOI: 10.1530/JME-15-0217
(C) 2016 Society for Endocrinology Printed in Great Britain
Published by Bioscientifica Ltd 